\title{
AMIANTO, MEIO AMBIENTE DO TRABALHO E RESPONSABILIDADE CIVIL DO EMPREGADOR
}

\author{
ASBESTOS, WORK ENVIRONMENT AND EMPLOYER'S CIVIL LIABILITY
}

\author{
Guilherme Guimarães Feliciano* \\ Olivia de Quintana Figueiredo Pasqualeto*
}

\begin{abstract}
Resumo:
Em que pese sua ampla utilização nos mais variados processos industriais, em diversos países, o amianto é uma substância comprovadamente nociva à saúde humana. Observando essa contradição entre o emprego do amianto nos processos produtivos e, portanto, sua presença no meio labor-ambiental, frente ao conhecimento de seus riscos, este artigo tem como objetivo compreender como se dá a responsabilidade civil do empregador pelo meio ambiente do trabalho, especialmente quando se vale do amianto na atividade econômica que empreende. A partir de pesquisa bibliográfica e documental, neste texto, discorre-se sobre meio ambiente do trabalho a partir de uma abordagem propedêutica, traçando linhas conceituais, bem como os princípios jurídicos que balizam seu estudo e tratamento jurídico; apuram-se os males causados pelo uso do amianto no trabalho e as possibilidades regulatórias do tema, com atenção à análise da Ação Direta de Inconstitucionalidade (ADI) ajuizada pela Associação Nacional dos Magistrados do Trabalho (ANAMATRA) e Associação Nacional dos Procuradores do Trabalho (ANPT) e para o julgamento, pelo Superior Tribunal Federal (STF), sobre a proibição da utilização do amianto no Brasil; estuda-se a responsabilidade civil do empregador em casos de desequilíbrio labor-ambiental em função do amianto. Em sede conclusiva, destaca-se a necessidade de proteção labor-ambiental a partir de mecanismos preventivos em face de acidentes e doenças oriundos do trabalho.
\end{abstract}

Palavras-chave: Amianto. Meio ambiente do trabalho. Poluição labor-ambiental. Responsabilidade civil do empregador.

\begin{abstract}
:
Despite its wide use in the most varied industrial processes, in several countries, asbestos is a substance that is proven to be harmful to human health. Observing this contradiction between the use of asbestos in the productive processes and, therefore, its presence in the labor environment, in the face of the knowledge of its risks, this article aims to understand the employer's civil liability for the work environment, especially when asbestos in the economic activity it undertakes. From a bibliographical and documentary research, in this text, it's analyzed: the work
\end{abstract}

\footnotetext{
* O Autor é Professor Associado II do Departamento de Direito do Trabalho e da Seguridade Social da Faculdade de Direito da Universidade de São Paulo e juiz Titular da $1^{\text {a }}$ Vara do Trabalho de Taubaté/SP. Livre-Docente em Direito do Trabalho pela FDUSP. Doutor em Direito Processual Civil pela Faculdade de Direito da Universidade de Lisboa. Doutor em Direito Penal pela FDUSP. Coordenador da Pós-Graduação "stricto sensu" em Direito e Processo do Trabalho da Universidade de Taubaté.

** A Coautora é Doutoranda em Direito pelo Departamento de Direito do Trabalho e da Seguridade Social da Faculdade de Direito da Universidade de São Paulo.
} 
environment based on a propedeutic approach, outlining its concept, as well as the legal principles that guide its study and legal treatment; the evils caused by the use of asbestos at work and the regulatory possibilities of the subject, with attention to the analysis of the Direct Action of Unconstitutionality (ADI) filed by the National Association of Labor Magistrates (ANAMATRA) and the National Association of Labor Prosecutors (ANPT) and for the judgment, by the Superior Federal Court (STF), on the prohibition of the use of asbestos in Brazil; the civil liability of the employer in cases of labor-environmental imbalance due to asbestos. In conclusion, it is important to highlight the need for environmental protection based on preventive mechanisms in the face of accidents and diseases from work.

Keywords: Asbestos. Work environment. Work environment pollution. Employer's civil liability.

\section{Introdução}

Zelar pelo meio ambiente do trabalho e pela saúde e segurança daqueles que lá se encontram é tarefa necessária, sobretudo quando a atividade econômica desenvolvida utiliza substâncias prejudiciais ao equilíbrio labor-ambiental, como se dá com o amianto. Ainda que comprovadamente nocivo não apenas à saúde dos trabalhadores, mas também aos consumidores e a todo o meio ambiente, o amianto continua sendo utilizado mundialmente em larga escala na produção de diversos itens, tais como telhas, caixas d'água, tecidos, tintas, instrumentos de laboratórios, papelão, dentre outras inúmeras aplicações.

Considerando esse descompasso entre prevenção pela não utilização do amianto e emprego de tal substância de forma irrestrita em diversos tipos de indústria (e.g. construção civil, bélica, aeroespacial, petrolífera, têxtil, naval, etc.), este artigo tem como objetivo analisar a responsabilidade civil do empregador pelo meio ambiente do trabalho, especialmente quando se vale do amianto na atividade econômica que empreende. Nesse contexto, pretende-se lançar luzes sobre os perigos do amianto para o meio ambiente do trabalho.

Para tanto, a partir de pesquisa bibliográfica e documental, este texto foi organizado em três grandes partes: $(i)$ no primeiro item, discorre-se sobre meio ambiente do trabalho a partir de uma abordagem propedêutica, buscando apresentar o conceito de meio ambiente do trabalho adotado pelos autores, bem como os princípios jurídicos que pautam seu estudo e proteção; (ii) no segundo item, debruça-se sobre as mazelas causadas pelo uso do amianto no trabalho, bem como as perspectivas de regulamentação de sua utilização no Brasil, com destaque para a análise da Ação Direta de Inconstitucionalidade (ADI) ajuizada pela Associação Nacional dos Magistrados do Trabalho (ANAMATRA) e Associação Nacional dos Procuradores do Trabalho (ANPT) e para o julgamento, pelo Superior Tribunal Federal (STF), sobre a proibição da utilização do amianto no Brasil; 
(iii) no terceiro item, dedica-se mais diretamente ao estudo da responsabilização civil do empregador em casos de desequilíbrio labor-ambiental em razão da utilização do amianto.

Por fim, encaminhando-se para a conclusão, evidencia-se a importância do cuidado com o meio ambiente do trabalho, especialmente a partir de estratégias de prevenção em face de acidentes e doenças oriundos do exercício laboral.

1. Meio ambiente do trabalho: abordagem propedêutica

A saúde e segurança dos trabalhadores, seu estudo e tratamento jurídico, não raro, são reduzidos a discussões mesquinhas sobre adicionais de insalubridade e periculosidade.

Contudo, muito além de tal monetização, a proteção do meio ambiente do trabalho e, consequentemente, da saúde e segurança dos trabalhadores, envolve abordagens mais amplas e sistêmicas, que promovam a higidez labor-ambiental em todos os âmbitos e evitem a concreção de todo tipo de risco, seja ele, físico (e.g. ruído, vibração, temperaturas extremas, pressões anormais, radiações ionizantes e não-ionizantes, etc.), químico (e.g. poeiras, névoas, fumos, gases e vapores, etc.), biológico (e.g. bactérias, fungos, helmintos, protozoários e vírus, etc.), ergonômico (e.g. esforço físico, levantamento de peso, postura inadequada, etc.) ou psicossocial (e.g. assédio moral, imposição e controle excessivo de metas, etc.).

Partindo do entendimento de que as questões labor-ambientais são complexas e que, portanto, devem ser compreendidas a partir de uma perspectiva gestáltica, passa-se ao delineamento do que se entende por meio ambiente do trabalho e à análise dos princípios que pautam seu estudo.

\subsection{Meio ambiente do trabalho: apontamentos conceituais}

Definir "meio ambiente do trabalho" não é uma missão simples, visto tratarse de conceito amplo e em constante construção. Assim, neste tópico, serão traçadas algumas linhas conceituais que compõem e balizam a noção de meio ambiente do trabalho, as quais, certamente, evoluirão progressivamente com o avanço das tecnologias e da ciência, inclusive da ciência jurídica.

Primeiro, importante frisar que o meio ambiente do trabalho faz parte do meio ambiente geral, lato sensu considerado e, dessa forma, seus conceitos estão intrinsecamente correlacionados. Dessa forma, para compreender aquele faz-se necessário, antes, assimilar o conceito deste.

Conforme definição legal dada pela lei que instituiu a Política Nacional do Meio Ambiente (Lei n. 6.938, de 1981), meio ambiente é entendido como "o conjunto de condições, leis, influências e interações de ordem física, química e biológica, que permite, 
abriga e rege a vida em todas as suas formas". Observa-se, contudo, que tal disposição normativa ( $i$ ) não expressa o caráter gestáltico do meio ambiente, já que o define como um conjunto, isto é, como a soma de elementos e não como um sistema, categoria esta que pressupõe uma necessária relação de interdependência e interconexão entre os elementos coexistentes; (ii) não inclui no conceito apresentado as interações de ordem psicossociais que interferem no meio ambiente. Por tais motivos, entende-se necessário complementar tal definição legal, tornando-a mais holística e adequada às características do meio ambiente.

Assim, o meio ambiente pode ser compreendido como um sistema de elementos que circundam todas as formas de vida, inclusive a humana, impactando e sendo impactado por elas, as quais também são partes integrantes desse sistema. Trata-se, como resume Derani (2008, p. 52), em uma perspectiva antropocêntrica, do "entourage do sujeito", isto é, o seu entorno, aquilo que o circunda, o meio em que se encontra. Sendo tal visão centrada na vida humana, não seria possível excluir o meio laboral de sua abrangência. Há, sob esse prisma,

uma indissociabilidade ontológica entre o meio ambiente
natural e o meio ambiente humano, de modo que o meio
ambiente - conceito e entidade - pode ser entendido
como "Gestalt" ali em acepção filosófica (significando que
a interpretação do objeto modifica ou condiciona a própria
experiência com o objeto) e aqui em acepção fenomênica, o
meio ambiente não deve ser tomado como soma de elementos
a isolar, analisar e dissecar, mas como sistema constituído
por unidades autônomas, manifestando uma solidariedade
interna e possuindo leis próprias, donde resulta que o modo
de ser de cada elemento depende da estrutura do conjunto e
das leis que o regem, não podendo nenhum dos elementos
preexistir ao conjunto (FELICIANO, 2002, p. 3).

O meio ambiente, portanto, envolve não apenas as dimensões natural, artificial e cultural, mas também a sua dimensão laboral, conforme dispõe o art. 200, inciso VIII da Constituição Federal, destacando constitucionalmente tal dimensão laborambiental.

Segundo, frisa-se que o meio ambiente do trabalho não se resume ao local de trabalho. Para além dos muros da empresa - espacial e material -, o meio ambiente do trabalho abrange também os próprios "instrumentos de trabalho, o modo de execução das tarefas" (MARANHÃO, 2017, p. 27), o clima organizacional, modalidade de pagamento, a maneira como o empregado é tratado pelo empregador e pelos seus pares (MELO, 2013), dentre inúmeros outros fatores - físicos, químicos, biológicos, ergonômicos, psicossociais - que influenciam sua vida no trabalho. 
Com as intensas e rápidas mudanças que ocorrem no mundo do trabalho, essa dimensão "extramuros" ganha cada vez mais destaque, evidenciando que o meio ambiente do trabalho não se restringe às dependências físicas do empregador, podendo se prolongar para outros espaços, como a própria residência do trabalhador, como se dá com aqueles que prestam trabalho à distância em sua casa (home office).

Por fim, terceiro apontamento, sendo parte do meio ambiente geral, o meio ambiente do trabalho também deve ser protegido, e seu equilíbrio, essencial à qualidade de vida das pessoas, deve ser preservado e promovido (tal como previsto em normas nacionais e internacionais de máxima estatura, art. $7^{\circ}$, inciso XXII e art. 225, caput, da Constituição Federal; art. 18 da Convenção Sociolaboral do Mercosul; Convenção n. 155 da Organização Internacional do Trabalho, art. 12 do Pacto Internacional de Direitos Econômicos, Sociais e Culturais), de modo a ser "impossivvel alcançar qualidade de vida sem ter qualidade de trabalho, nem se pode atingir meio ambiente equilibrado e sustentável ignorando o meio ambiente do trabalho" (OLIVEIRA, 1998, p. 78-79).

\subsection{Princípios jurídicos orientadores do Direito Ambiental do Trabalho}

O Direito Ambiental do Trabalho, um ramo afeto ao Direito Ambiental, é norteado pelos princípios que orientam a proteção do meio ambiente lato sensu considerado. Assim, são princípios fundantes do Direito Ambiental do Trabalho, sem excluir outros secundários que eventualmente sejam tratados na doutrina: (i) o princípio da prevenção, (ii) o princípio da precaução, (iii) o princípio da melhoria contínua, (iv) o princípio da informação-participação e (v) o princípio do poluidor-pagador.

Os princípios da prevenção $(i)$ e da precaução (ii), apesar de semelhantes e corriqueiramente tomados como sinônimos, tecnicamente não se equivalem.

O princípio da prevenção (i) balizou a Declaração de Estocolmo (1972) ${ }^{1}$ e pressupõe o dever (por parte de todos, sejam atores púbicos ou privados) de evitar a concreção de riscos conhecidos, cientificamente comprovados que são danosos ao meio ambiente, impedindo "a ocorrência de atentados ao meio ambiente mediante meios apropriados, ditos preventivos” (PRIEUR, 2001, p. 306).

Diferentemente da prevenção, o princípio da precaução (ii), sintetizado no art. 15 da Declaração do Rio sobre Meio Ambiente e Desenvolvimento, preconiza

\footnotetext{
"Princípio 5: Os recursos não renováveis da terra devem empregar-se de forma que se evite o perigo de seu futuro esgotamento e se assegure que toda a humanidade compartilhe dos beneficios de sua utilização. [...] Princípio 7: Os Estados deverão tomar todas as medidas possíveis para impedir a poluição dos mares por substâncias que possam por em perigo a saúde do homem, os recursos vivos e a vida marinha, menosprezar as possibilidades de derramamento ou impedir outras utilizações legítimas do mar." (ORGANIZAÇÃO DAS NAÇÕES UNIDAS, 1972, grifo nosso).
} 
que "quando houver ameaça de danos sérios ou irreversíveis, a ausência de absoluta certeza cientifica não deve ser utilizada como razão para postergar medidas eficazes e economicamente viáveis para prevenir a degradação ambiental"' (ONU, 1992). Em outras palavras, ainda que não haja comprovação científica cabal sobre os riscos de determinada atividade, entende-se que há o dever, por parte dos agentes públicos ou particulares, de evitá-lo.

Assim, ressalta-se que o ponto de divergência entre $(i)$ e (ii) é a certeza científica sobre os possíveis danos que determinada atividade prova ao meio ambiente, nele incluído o meio ambiente do trabalho. Importa ressaltar que o princípio da precaução não pretende inviabilizar ou proibir toda e qualquer atividade que cause algum tipo de impacto no meio ambiente; "não se trata da precaução que tudo impede ou que em tudo vê catástrofes ou males. O princípio da precaução visa à durabilidade da sadia qualidade de vida das gerações humanas à continuidade da natureza existente no planeta" (MACHADO, 2010, p. 72), ultrapassando a barreira da cientificidade para proteger bens e direitos (tais como a vida e saúde humana) que não podem esperar o avanço das ciências e das tecnologias, pois, caso maculados, podem ser irreparáveis.

O princípio da melhoria contínua (iii) indica que a melhoria do meio ambiente, inclusive do meio ambiente do trabalho, deve ser buscada frequentemente, procurando sempre estar no mesmo compasso do mais avançado estado da técnica. Assim, não basta fornecer equipamentos de proteção aos trabalhadores; mais do que isso, é necessário atentar-se constantemente a novas tecnologias que eliminam o risco do meio labor-ambiental ou, se isso ainda não for possível, fornecer equipamentos de proteção mais protetivos; trocá-los quando do lançamento de outros mais modernos e seguros. Nesse sentido, segue o art. $7^{\circ}$, XXII da Constituição Federal, que dispõe sobre a redução de riscos inerentes ao trabalho, e o item 6.1 do Anexo 13-A (Benzeno) da Norma Regulamentadora (NR) n. 15 (Atividades e operações insalubres), que aborda o princípio de forma expressa:

o princípio da melhoria contínua parte do reconhecimento de que o benzeno é uma substância comprovadamente carcinogênica, para a qual não existe limite seguro de exposição. Todos os esforços devem ser despendidos continuamente no sentido de buscar a tecnologia mais adequada para evitar a exposição do trabalhador ao benzeno. (grifo nosso).

Para que haja efetiva observância dos princípios analisados acima, é preciso que todos aqueles que participam do meio ambiente colaborem para a sua preservação. Assim também se dá no meio ambiente do trabalho, no qual todos os atores envolvidos devem colaborar para a manutenção de seu equilíbrio, inclusive os trabalhadores. Neste tocante, merece atenção o princípio da informação-participação (iv), segundo o qual 
os trabalhadores têm o direito de participar das decisões tomadas sobre o meio laboral, tal como ocorre nas Comissões Internas de Acidentes do Trabalho (CIPA) e, para que essa participação seja possível, adequada e não meramente pro forma, é preciso que também tenham a garantia de acesso à totalidade das informações sobre as questões labor-ambientais (informação), configurando ao empregador um verdadeiro dever prestar informações aos trabalhadores sobre o meio laboral em que se inserem. Tal dever consta no rol de deveres do empregador previsto no item 1.7 da NR n. 1, segundo o qual:

\subsection{Cabe ao empregador:}

a) cumprir e fazer cumprir as disposições legais e regulamentares sobre segurança e medicina do trabalho;

b) elaborar ordens de serviço sobre segurança e saúde no trabalho, dando ciência aos empregados por comunicados, cartazes ou meios eletrônicos.

c) informar aos trabalhadores:

I - os riscos profissionais que possam originar-se nos locais de trabalho;

II - os meios para prevenir e limitar tais riscos e as medidas adotadas pela empresa;

III - os resultados dos exames médicos e de exames complementares de diagnóstico aos quais os próprios trabalhadores forem submetidos;

IV - os resultados das avaliações ambientais realizadas nos locais de trabalho.

[...] (grifo nosso).

Nesse mesmo sentido, conforme dispõe o art. 13 da Convenção n. 161 da OIT, "todos os trabalhadores devem ser informados dos riscos para a saúde inerentes a seu trabalho". Para tanto, a informação transmitida aos trabalhadores deve ser clara e objetiva, com linguagem acessível e amplamente divulgada (CLERC, 1982).

Acolhendo tal princípio, a NR n. 9 (Programa de Prevenção de Riscos Ambientais), em seu item 9.5.2, faz menção expressa ao direito (dever do empregador) de informação do trabalhador, dispondo que "os empregadores deverão informar os trabalhadores de maneira apropriada e suficiente sobre os riscos ambientais que possam originar-se nos locais de trabalho e sobre os meios disponíveis para prevenir ou limitar tais riscos e para proteger-se dos mesmos".

Por fim, caso o dano ambiental - nele incluído os danos labor-ambientais tenha se concretizado, há o princípio do poluidor-pagador $(v)$ - relevante em matéria de responsabilidade civil do poluidor (empregador) -, segundo o qual, aquele que polui o meio 
ambiente tem a obrigação de repará-lo. Nesse sentido, aquele que causa desequilíbrios no meio ambiente do trabalho deve arcar com os custos necessários para repará-lo. Tal mandamento é expresso na Lei n. 6.938/81, em seu art. 4, VII, segundo deve-se impor ao poluidor ambiental a "obrigação de recuperar elou indenizar os danos causados e, ao usuário, da contribuição pela utilização de recursos ambientais com fins econômicos".

Tais princípios, interpretados de forma sistêmica, proporcionam unidade ao sistema jurídico de proteção do meio ambiente do trabalho, firmando a necessidade de tratar tal temática a partir de uma visão preventiva, buscando: primeiro, eliminar os riscos presentes no meio labor-ambiental - sejam riscos, físicos, químicos, biológico ou psicossociais -; segundo, caso não seja possível extingui-los, o dever de reduzi-los ao máximo, inclusive fornecendo equipamentos de proteção coletiva e individual aos trabalhadores; relegando a situações de caráter estritamente excepcional a sua monetização.

\section{O trabalho com amianto: mazelas e perspectivas}

Amianto (latim) ou asbesto (grego) são nomes genéricos para designar uma série de minérios encontrados na natureza, tais como minerais constituídos por silicatos de ferro, alumínio, magnésio, cálcio, que se apresentam sob forma fibrosa e dividem-se em dois grupos: os anfibólios, que "representam menos de 5\% de todo o amianto explorado e consumido no mundo, estão banidos da maior parte do planeta" (INSTITUTO NACIONAL DO CÂNCER); e as serpentinas, tipo mais utilizado, cuja variedade mais comum é a crisotila ou "amianto branco", caracterizado por apresentar fibras curvas e maleáveis.

Seu uso generalizado iniciou-se em finais do século XIX, já sob a segunda Revolução Industrial, graças a sua abundância na natureza e ao baixo custo de exploração. Seu sucesso, sobretudo na década de 1970, quando atinge seu auge, deve-se ao fato de ter sido

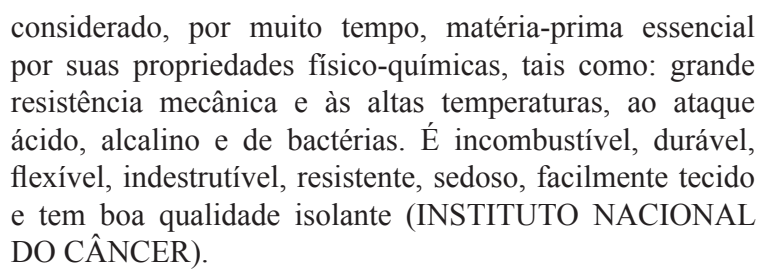

Contudo, o avanço da ciência e das novas tecnologias, especialmente nos países desenvolvidos, permitiu descobrir que a utilização do amianto pode provocar danos irreversíveis à saúde daqueles que entram em contato com tal substância, a exemplo dos trabalhadores. Ademais, o contato com o amianto é particularmente preocupante porque tem um "período de dormência excepcionalmente longo entre a exposição e o 
desenvolvimento do mesotelioma, que chega a 40 anos. Por esta razão, o número de doenças relacionadas ao amianto continuará a subir, mesmo em países que o proibiram há muitos anos" (ORGANIZAÇÃO MUNDIAL DA SAÚDE, 2015, p. 7).

Ainda assim, sendo seus riscos conhecidos, segundo dados da Organização Mundial da Saúde (2016), há atualmente no mundo cerca de 125 milhões de pessoas que continuam expostas ao amianto em seu ambiente de trabalho. Calcula-se que a metade das mortes por câncer profissional são causadas pelo contato com o amianto, além de milhões de mortes atribuídas à exposição doméstica à substância. Nesse cenário, vale ressaltar a necessidade de constante preocupação com a utilização do amianto, o qual teve seus efeitos letais cientificamente demonstrados (ORGANIZAÇÃO MUNDIAL DA SAÚDE, 2015, p. 6), porém continua sendo utilizado por diversas indústrias.

\subsection{Amianto, câncer profissional e Convenção n. 139 da OIT}

A exposição ao amianto se dá por inalação (e, em menor medida por ingestão) durante a extração, trituração e utilização da sustância ao longo do processo industrial, bem como pela utilização e contato com produtos que contém amianto em sua composição. Dentre as principais enfermidades causadas pela exposição ao amianto, estão a asbestose ${ }^{2}$ e os diversos tipos de câncer ${ }^{3}$ (pulmão, laringe, trato digestivo, ovário, mesotelioma, ${ }^{4}$ etc. $),{ }^{5}$ sendo esta a doença mais grave fruto da exposição ao amianto.

\footnotetext{
2 "A doença é causada pela deposição de fibras de asbesto nos alvéolos pulmonares, provocando uma reação inflamatória, seguida de fibrose e, por conseguinte, sua rigidez, reduzindo a capacidade de realizar a troca gasosa, promovendo a perda da elasticidade pulmonar e da capacidade respiratória com sérias limitações ao fluxo aéreo e incapacidade para o trabalho. Nas fases mais avançadas da doença esta incapacidade pode se estender até para a realização de tarefas mais simples e vitais para a sobrevivência humana" (INSTITUTO NACIONAL DO CÂNCER).

3 "Câncer é o nome dado a um conjunto de mais de 100 doenças que têm em comum o crescimento desordenado (maligno) de células que invadem os tecidos e órgãos, podendo espalhar-se (metástase) para outras regiões do corpo. Dividindo-se rapidamente, essas células tendem a ser muito agressivas e incontroláveis, determinando a formação de tumores (acúmulo de células cancerosas) ou neoplasias malignas. Os diferentes tipos de câncer correspondem aos vários tipos de células do corpo. Outras características que diferenciam os diversos tipos de câncer entre si são a velocidade de multiplicação das células e a capacidade de invadir tecidos e órgãos vizinhos ou distantes (metástases)". (INSTITUTO NACIONAL DO CÂNCER, 2012b).

4 "O mesotelioma é uma forma rara de tumor maligno, mais comumentemente atingindo a pleura, membrana serosa que reveste o pulmão, mas também incidindo sobre o peritônio, pericárdio e a túnica vaginal e bolsa escrotal. Está se tornando mais comum em nosso país, já que atingimos o período de latência de mais de 30 anos da curva de crescimento da utilização em escala industrial no Brasil, que deu-se durante o período conhecido como o "milagre econômico", na década de 70. Não se estabeleceu nenhuma relação do mesotelioma com o tabagismo, nem com doses de exposição. O Mesotelioma maligno pode produzir metátases por via linfática em aproximadamente 25\% dos casos" (INSTITUTO NACIONAL DO CÂNCER).

5 "Além das doenças descritas, o amianto pode causar espessamento na pleura e diafragma, derrames pleurais, placas pleurais e severos distúrbios respiratórios" (INSTITUTO NACIONAL DO CÂNCER).
} 
A via de absorção (seja ela respiratória, oral ou cutânea), a duração e a frequência da exposição aos agentes nocivos influenciam o grau de toxidade. Contudo, importante salientar que não existem níveis seguros de exposição a agentes carcinogênicos (ORGANIZAÇÃO MUNDIAL DA SAÚDE, 2015), indicando que qualquer contato com um agente carcinogênico pode ser um ponto de partida para o desenvolvimento de doenças.

Além do amianto, há uma diversidade de substâncias classificadas pela Organização Mundial da Saúde (OMS) como cancerígenas: desde elementos mais associados ao desenvolvimento de tumores malignos, como o já citado amianto (ou asbesto), até produtos aparentemente inofensivos, como poeiras de madeira e de couro, medicamentos (e.g. antineoplásicos, por exemplo), etc.

No tocante ao meio ambiente do trabalho, há uma série de agentes cancerígenos que estão ali presentes mais frequentemente: metais pesados, agrotóxicos, solventes orgânicos, formaldeídos e poeiras (amianto e sílica). Conforme estudo realizado pelo Instituto Nacional do Câncer (2012a), "pelo menos 19 tipos de tumores malignos, como os de pulmão, pele, fígado, laringe, bexiga e leucemias podem estar relacionados à ocupação do paciente".

Contudo, esse nexo entre meio ambiente do trabalho e o aparecimento do câncer é subdimensionado graças à dificuldade de se estabelecer uma relação entre os dois na própria consulta médica: "raramente o médico pergunta ao paciente qual a ocupação dele" (INSTITUTO NACIONAL DO CÂNCER, 2012a). Por isso, a importância dos profissionais da saúde conversarem com os pacientes diagnosticados com câncer sobre sua rotina laboral ao longo da vida. "Só assim será possível identificar e registrar os casos de câncer relacionados ao trabalho no Sistema Nacional de Agravos do Ministério da Saúde" (INSTITUTO NACIONAL DO CÂNCER, 2012a), mapeando sua taxa de incidência, causas mais comuns, tipos mais frequentes, dentre outras informações úteis para embasar uma política pública de saúde para esse fim e para dar efetividade às obrigações assumidas em função da ratificação da Convenção n. 139 da OIT. ${ }^{6}$

A Convenção n. 139 da OIT dispõe sobre a prevenção e o controle de riscos profissionais causados por substâncias ou agentes cancerígenos, estabelecendo, aos Estados que a ratificaram, diferentes deveres para proteção do meio ambiente do trabalho e da saúde dos trabalhadores. Neste tocante, todo membro que tiver ratificado tal Convenção deverá “determinar periodicamente as substâncias e agentes cancerígenos

6 Convenção aprovada na $59^{\mathrm{a}}$ reunião da Conferência Internacional do Trabalho, em Genebra, no ano de 1974. Entrou em vigor no plano internacional em 10 de junho de 1976 e ratificada pelo Brasil em junho de 1990 (Promulgação pelo Decreto n. 157, de 2 de junho de 1991 e vigência nacional a partir de 27 de junho de 1991). 
aos quais estará proibida a exposição no trabalho, ou sujeita a autorização ou controle", atendendo ao princípio da melhoria contínua, e levar "em consideração os dados mais recentes contidos nos repertórios de recomendações práticas ou guias que a Secretaria Internacional do Trabalho possa elaborar" (art. $1^{\circ}$ ); "procurar de todas as formas substituir as substâncias e agentes cancerígenos a que possam estar expostos os trabalhadores durante seu trabalho por substâncias ou agentes não cancerígenos ou por substâncias ou agentes menos nocivos" e "a duração e os níveis dessa exposição devem ser reduzidos a o mínimo compatível com a segurança" (art. $2^{\circ}$ ), atendendo aos princípios da prevenção e precaução e buscando um risco mínimo regressivo; "prescrever as medidas a serem tomadas para proteger os trabalhadores contra os riscos de exposição a substâncias ou agentes cancerígenos" (art. $3^{\circ}$ ); adotar medidas para que os trabalhadores recebam "toda a informação disponível sobre os perigos que representam tais substâncias e sobre as medidas a serem aplicadas", observando o princípio da informação (art. $4^{\circ}$ ); "adotar medidas para assegurar que sejam proporcionados aos trabalhadores os exames médicos ou os exames ou investigações de natureza biológica ou de outro tipo que permitam avaliar o estado de saúde dos trabalhadores" (art. $5^{\circ}$ ).

Além das obrigações acima, de caráter eminentemente preventivo, a Convenção ainda estabelece que os membros que a ratificaram devem, ainda, proporcionar serviços de inspeção apropriados para zelar pela aplicação das disposições da presente Convenção ou certificar-se de que se exerce uma inspeção adequada no que se refere ao meio ambiente do trabalho e, consequentemente, a saúde e segurança dos trabalhadores.

\subsection{Aspectos jurídicos em relação ao uso do amianto no Brasil}

O contexto jurídico brasileiro em relação ao amianto é diversificado, encontrando-se abordagens sobre o tema no âmbito legislativo (federal, estadual e municipal), administrativo, jurisprudencial. Neste item, serão analisadas as normas existentes sobre a utilização do amianto no Brasil e o posicionamento do Superior Tribunal Federal sobre a (in)constitucionalidade do art. $2^{\circ}$ da Lei n. 9.055/1995.

\subsubsection{O amianto na legislação brasileira}

O tratamento jurídico dado ao amianto no Brasil não é unívoco: há uma lei federal sobre o tema, variadas leis estaduais e municipais que restringem a sua utilização, além de uma norma administrativa sobre saúde e segurança do trabalho (Anexo 12 da Norma Regulamentadora n. 15, sobre os limites de tolerância do asbesto), tratada aqui como legislação em sentido lato.

No âmbito federal, a extração, a industrialização, a utilização, a comercialização e o transporte do amianto, bem como dos produtos que o contenham, são 
disciplinados pela Lei n. 9.055/1995 e, mais especificamente, a exposição labor-ambiental a tal substância é regulamentada no Anexo 12 da NR n. 15.

A Lei n. 9.055, de 1 de junho de 1995, proíbe o uso do amianto em sua variedade anfibólio (art. $1^{\circ}$, inciso I), a pulverização de todos os tipos de fibras, inclusive do amianto crisotila (art. $1^{\circ}$, inciso II), a venda a granel de fibras em pó de qualquer tipo, inclusive do amianto crisotila (art. $1^{\circ}$, inciso III); e autoriza o uso do amianto crisotila, bem como demais fibras, naturais e artificiais de qualquer origem, ${ }^{7}$ de acordo com balizamentos previstos na própria lei (art. $2^{\circ}$ ).

No tocante às questões labor-ambientais, a Lei n. 9.055/1995 preocupou-se em reiterar que as normas de saúde e segurança do trabalho (art. $3^{\circ}$ ), especialmente os limites de tolerância (art. $7^{\circ}$ ), previstos na NR n. 15 devem ser observados, indicando a obrigatoriedade da realização de exames médicos (art. $5^{\circ}$ ) e listagem dos trabalhadores que foram expostos ao amianto (art. $5^{\circ}$, caput).

Seguindo essa mesma lógica, a NR n. 15, em seu Anexo 12, também proíbe a utilização de qualquer tipo de amianto do grupo anfibólio e dos produtos que contenham essas fibras, permitindo a utilização do amianto na variedade crisotila, dentro do limite de tolerância de 2,0 f/cm3 (item 12) e de acordo com contornos estabelecidos na NR.

Dentre outras, tais contornos estabelecem a proibição do trabalho de menores de 18 anos em ambientes onde possa haver a poeira do amianto (item 6); necessidade de rotulagem do produto de forma adequada, suficiente e compreensível por parte dos fornecedores, inclusive quanto às instruções de uso, atendendo ao princípio da informação (itens 9 e 10); dever de realizar avaliação ambiental em relação à poeira do amianto em intervalos de, no máximo, 6 meses (item 11), a qual deverá ser informada aos trabalhadores (item 11.3) e acompanhada pelos sindicatos (item 11.2), atendendo aos princípios da prevenção e precaução e da informação-participação; "o empregador deve garantir informações e treinamento aos trabalhadores, com frequência mínima anual, priorizando os riscos e as medidas de proteção e controle devido à exposição ao asbesto" (item 20), observando os princípios da prevenção, precaução e informação.

Contudo, apesar de tais balizamentos, ambas as normas de âmbito federal se olvidaram da recomendação inequívoca da Organização Mundial da Saúde de que não há forma segura de contato com o amianto, isto é, qualquer exposição a tal substância é potencialmente lesiva (inclusive, cancerígena) ao ser humano (ORGANIZAÇÃO MUNDIAL DA SAÚDE, 2015, p. 6). Ademais, ainda que permitissem a manipulação do amianto crisotila, também se olvidaram de atualizar (e rebaixar) ${ }^{8}$ seus limites de

Conforme dispõe o art. $2^{\circ}$, parágrafo único da Lei n. 9.055/1995, "para os efeitos desta Lei, consideram-se fibras naturais e artificiais as comprovadamente nocivas à saúde humana”.

8 Dados da Occupational Safety and Health Administration (OSHA), órgão norte-americano dedicado às 
tolerância com base em normas internacionais sobre saúde e segurança do trabalho, conforme interpretação analógica do item 9.3.5.1, “c" da NR n. $9,{ }^{9}$ o que consagraria o princípio da melhoria contínua.

No âmbito estadual, há leis mais restritivas do que a lei federal, proibindo a utilização do amianto. Merecem destaque a Lei n. 10.813/2001, do estado de São Paulo, dispõe sobre a proibição de importação, extração, beneficiamento, comercialização, fabricação e a instalação, no Estado de São Paulo, de produtos ou materiais contendo qualquer tipo de amianto; a Lei n. 12.684/2007 (regulamentada pelo decreto estadual n. 58.695/2012), também do estado de São Paulo, que proíbe o uso, no estado de São Paulo de produtos, materiais ou artefatos que contenham quaisquer tipos de amianto ou asbesto ou outros minerais que, acidentalmente, tenham fibras de amianto na sua composição; a Lei n. 2.210/2001, do estado de Mato Grosso do Sul, proibindo a comercialização de produtos à base de amianto destinados à construção civil no âmbito de Mato Grosso do Sul; a Lei n. 3.569/2001, do estado do Rio de Janeiro, que dispõe sobre a substituição progressiva da produção e da comercialização de produtos que contenham amianto; a Lei n. 4.314/2001, do estado do Rio de Janeiro, que dispõe sobre as obrigações das empresas de fibrocimento pelos danos causados à saúde dos trabalhadores no âmbito do estado do Rio de Janeiro; o Decreto n. 40.674/20017, também do estado carioca, sobre a vedação aos órgãos da administração direta e indireta de utilização de qualquer tipo de amianto; a Lei n. 11.643/2001, do estado do Rio Grande do Sul, que proíbe a produção e comercialização de produtos à base de amianto no estado; a Lei n. 12.589/2004, do estado de Pernambuco, sobre a proibição do amianto nas obras públicas; Lei n. 9.583/2011, que proíbe o uso de materiais ou artefatos que contenham quaisquer tipos de amianto ou asbesto ou outros minerais que, acidentalmente, tenham fibras de amianto na sua composição.

Todas essas leis foram objeto de ações judiciais para declaração de sua inconstitucionalidade em face da Lei Federal n. 9.095/1995 que autoriza a produção e o uso do amianto crisotila no Brasil. Destaca-se que as ações foram majoritariamente propostas pelo estado de Goiás, um dos maiores produtores de amianto crisotila, já que no município

questões relacionadas à saúde e segurança no trabalho indica como limite de tolerância do amianto o índice de 0,1 fibra por centímetro cúbico em uma média de 8 horas de trabalho e a possibilidade excepcional de exposição, durante 30 minutos, no máximo, a 1 fibra de amianto por centímetro cúbico (OCCUPATIONAL SAFETY AND HEALTH ADMINISTRATION, 2014, p. 1). Note-se que o limite de tolerância fixado na legislação brasileira é de 2 fibras de amianto por centímetro cúbico, isto é, um limite 20 vezes maior do que aquele fixado pela OSHA.

9 “c) quando os resultados das avaliações quantitativas da exposição dos trabalhadores excederem os valores dos limites previstos na NR-15 ou, na ausência destes os valores limites de exposição ocupacional adotados pela ACGIH - American Conference of Governmental Industrial Higyenists, ou aqueles que venham a ser estabelecidos em negociação coletiva de trabalho, desde que mais rigorosos do que os critérios técnicolegais estabelecidos". 
de Minaçu/GO está localizada uma das três maiores minas de amianto crisotila do mundo, a "Cana Brava", sob o argumento de que, além de ferir dispositivo constitucional, tais normas estaduais prejudicariam a economia no estado de Goiás (e.g. ADI n. 2.656, ADI n. 2.396); e pela Confederação Nacional dos Trabalhadores na Indústria, defendendo que a proibição de tal substância feriria o direito ao trabalho daqueles que laboram na indústria do amianto (e.g. ADI n. 3.937, ADI n. 3.406). A jurisprudência oscilou no tratamento dessas diversas ações, ora julgando-as procedentes, ora improcedentes. Nos itens seguintes, analisar-se-á uma das ADIs propostas que mais se relaciona com a preocupação do equilíbrio labor-ambiental e o julgamento mais recente do Supremo Tribunal Federal sobre o tema.

No âmbito municipal, em menor quantidade, também há iniciativas de proibição do uso do amianto. Merecem destaque a Lei Municipal n. 3.316/2000, do município de Mogi Mirim (SP), que proíbe os órgãos da administração pública direta e indireta de adquirir e utilizar materiais produzidos com amianto em suas edificações; a Lei Complementar n. 90/2000, do município de Osasco (SP), que proíbe a utilização de materiais produzidos com amianto nas construções públicas e privadas; a Lei n. 13.113/2001, do município de São Paulo (SP), que proíbe o uso de qualquer material e equipamento à base de amianto na construção civil; a Lei n. 9.264/2001, do município de Ribeirão Preto (SP), que também proíbe o uso do amianto na construção civil; a Lei n. 3.425/2001, do município de Barretos (SP), que dispõe sobre a proibição do uso do amianto na construção civil; a Lei Complementar n. 332/2001, do município de Jundiaí (SP), que proíbe o uso de materiais produzidos com amianto nas construções públicas e privadas no município; Lei municipal de Amaro (SP) n. 2.672/2001, que a proíbe a fabricação e estabelece restrições ao uso e comercialização do amianto, definindo prazos para banimento de materiais produzidos com qualquer forma de amianto no município; Lei n. 5.693/2001, do município de Guarulhos (SP), que pró́be a utilização do amianto na construção civil; Lei municipal de Taboão da Serra n. 1.368/2001, que proíbe o uso do amianto nas construções públicas; a Lei n. 10.874/2001 do município de Campinas (SP), que proíbe a fabricação, estabelece restrições ao uso e comercialização e define prazos para banimento de materiais produzidos com qualquer forma de amianto ou de outros minerais ou materiais que os contenham em sua composição; a Lei Municipal n. 2.738/2003 do município de Santa Barbara D’Oeste (SP) que proíbe a fabricação e regulamenta a comercialização de produtos à base de amianto; a Lei n. 2.712/1998 do município do Rio de Janeiro (RJ), que dispõe que os produtos de cimento amianto comercializados no município do Rio de Janeiro deverão estampar por meio de carimbo ou adesivo, em tamanho que torne perfeitamente visível a seguinte frase: "Este produto pode causar danos à saúde"; Lei n. 2.762/1997, do município do Rio de Janeiro, que proíbe a utilização de telhas de amianto em prédios municipais. 
Interessante notar que grande parte das leis municipais dispõe sobre a proibição da utilização do amianto na indústria da construção civil; justamente, uma das indústrias que mais utiliza materiais à base de tal substância, especialmente em telhas e cimentos.

\subsubsection{ADI ajuizada pela ANAMATRA e ANPT}

Cientes dos riscos labor-ambientais gerados pela exposição humana ao amianto e no âmbito de suas finalidades institucionais, ${ }^{10}$ em 2 de abril de 2008, a Associação Nacional dos Magistrados do Trabalho (ANAMATRA) e a Associação Nacional dos Procuradores do Trabalho (ANPT), em conjunto, ajuizaram uma Ação Direta de Inconstitucionalidade (ADI n. 4.066/DF), com pedido liminar, para que seja declarada a inconstitucionalidade do art. $2^{\circ}$ da Lei n. 9.055, de $1^{\circ} .6 .1995$, em face da violação aos arts. $1^{\circ}$, III e IV, 170, caput e VI, 196 e 225, da Constituição Federal.

As razões para o ajuizamento da ADI centram-se, sobretudo, nas mazelas que o amianto pode trazer à saúde do ser humano, especialmente dos trabalhadores que estão em contato direto e prolongado com tal substância; e a todo o meio ambiente, que padece de danos irreparáveis em "decorrência da total ausência de cuidados apropriados com os residuos provenientes da atividade mineradora, em muitos casos despejados a céu aberto, em áreas de livre acesso e até mesmo em locais onde se faz presente a ocupação humana" (ANAMATRA; ANPT, 2008, p. 25).

Ademais, demonstra-se ao longo da peça que o Brasil anda em “descompasso com os rumos tomados pelo cenário internacional, onde o amianto, em todas as suas modalidades, vem sendo sistematicamente abolido, ${ }^{11}$ não só pelos países desenvolvidos,

10 Dentre as finalidades da Associação Nacional dos Procuradores do Trabalho (ANPT) constam as de "promover a defesa judicial e extrajudicial dos direitos e interesses coletivos e individuais dos associados, relacionados à atividade profissional, desde que compativeis com as suas finalidades", de "colaborar com os Poderes Públicos no desenvolvimento da justiça, na defesa dos interesses sociais" e de "desenvolver ações nas áreas específicas das funções institucionais do Ministério Público" (grifo nosso) e, no que tange à Associação Nacional dos Magistrados da Justiça do Trabalho (ANAMATRA), o art. $2^{\circ}, \S 3^{\circ}$ de seu estatuto é expresso ao demonstrar a relação de pertinência entre o objeto da ação e as suas finalidades institucionais, ao dispor que: "A ANAMATRA, tem por finalidade congregar Juizes do Trabalho em torno de interesses comuns, promovendo maior aproximação, cooperação e solidariedade, defendendo e representando os seus interesses e prerrogativas perante as autoridades e entidades nacionais e internacionais, pugnando pelo crescente prestígio da Justiça do Trabalho. [...] $\S 3^{\circ}$ A ANAMATRA deverá atuar na defesa dos interesses da sociedade, em especial, pela valorização do trabalho humano, pelo respeito à cidadania e pela implementação da justiça social, pugnando pela preservação da moralidade pública, da dignidade da pessoa humana, da independência dos Poderes e dos princípios democráticos." (grifo nosso).

$11 \mathrm{Na}$ ADI, as autoras apresentam o seguinte panorama dos países que aboliram e baniram o amianto: "Islândia: 1983 - Noruega: 1984 - El Salvador: (metade da década de 80) - Dinamarca: 1986 - Suécia: 1986 - Suiça: 1989 - Áustria: 1990 - Holanda: 1991 - Finlândia: 1992 - Itália: 1992 - Alemanha: 1993 França: 1996 - Eslovênia: 1996 - Polônia: 1997 - Principado de Mônaco: 1997 - Bélgica: 1998 - Arábia 
mas também por muitas nações ainda em desenvolvimento" (ANAMATRA; ANPT, 2008, p. 12), registrando que

o progresso tecnológico experimentado nas últimas décadas permitiu o desenvolvimento de fibras alternativas ao amianto, capazes de viabilizar o prosseguimento das atividades econômicas exploradas pelo setor de fibrocimento, sem impor aos trabalhadores e à população em geral o contato com a poeira cancerígena emanada do asbesto (ANAMATRA; ANPT, 2008, p. 15).

As fibras referidas na ADI, tais como fios de polivinílico álcool (PVA) e de polipropileno (PP), além de serem economicamente viáveis e figurarem como uma alternativa adequada ao uso do amianto, "têm sua utilização recomendada pela Organização Mundial de Saúde (Critério 203/1998 - OMS)".

Por tais razões, as autoras requerem que seja deferida a liminar, com a consequente suspensão da eficácia do dispositivo legal impugnado, até o julgamento final da ADI e que seja julgada integralmente procedente a ação, com vistas à declaração de inconstitucionalidade do art. $2^{\circ}$ da Lei n. 9.055/95.

\subsubsection{Julgamento da (in)constitucionalidade do uso do amianto pelo STF}

Em 24 de agosto de 2017, o Supremo Tribunal Federal (STF) concluiu o julgamento da ADI n. 4.066/DF ajuizada pela ANAMATRA e ANPT em 2008.

O Tribunal, por maioria, conheceu da ação, reconhecendo a legitimidade ativa das autoras, vencidos os Ministros Alexandre de Moraes e Marco Aurélio. No mérito, o Tribunal computou cinco votos (dos Ministros Rosa Weber (Relatora), Edson Fachin, Ricardo Lewandowski, Celso de Mello e Cármen Lúcia) pela procedência da ação, e quatro votos (dos Ministros Alexandre de Moraes, Luiz Fux, Gilmar Mendes e Marco Aurélio) pela improcedência da ação, e, por não se ter atingido o quórum exigido pelo artigo 97 da Constituição, não se pronunciou a inconstitucionalidade do art. $2^{\circ}$ da Lei 9.055/1995, em julgamento destituído de eficácia vinculante. Impedidos os Ministros Roberto Barroso e Dias Toffoli. Ausente, justificadamente, o Ministro Gilmar Mendes. Presidiu o julgamento a Ministra Cármen Lúcia. Plenário, 24.8.2017. (grifo nosso).

Saudita: 1998 - Burkina-Faso: 1998 - Inglaterra: 1999 - País de Gales: 1999 - Irlanda do Norte: 1999 Escócia: 1999 - República da Irlanda/Eire: 2000 - Lativia: 2001 - Chile: 2001 - Argentina: 2001 - Espanha: 2002 - Luxemburgo: 2002 - Austrália: 2003 - Liechtenstein - Emirados Árabes - Nova Zelândia - República Checa - Vietnã: 2004 - Portugal: 2005 - Grécia: 2005 - Japão: 2004 - Honduras: 2004 - Uruguai: 2002 Seychelles - Gabão - África do Sul: 2004" (ANAMATRA; ANPT, 2008, p. 13). 
Nesse sentido, apesar da maioria (simples) do Tribunal ter entendido ser o art. $2^{\circ}$ da Lei n. 9.095/1995 inconstitucional, por 5 votos a 4, a decisão não tem efeito vinculante porque não se deu por maioria absoluta, conforme exigência do art. 97 da Constituição Federal, segundo o qual "somente pelo voto da maioria absoluta de seus membros ou dos membros do respectivo órgão especial poderão os tribunais declarar a inconstitucionalidade de lei ou ato normativo do Poder Público".

Na prática, como a decisão do STF não tem efeito vinculante, visto não ter atingido a maioria qualificada dos votos, os juízes e tribunais do país ficam livres para decidir, de acordo com o caso concreto, se o uso do amianto e as leis estaduais e municipais são (in)constitucionais, exercendo o controle difuso de constitucionalidade.

Na mesma data, o STF julgou também a ADI n. 3.937/SP, ajuizada pela Confederação Nacional dos Trabalhadores na Indústria sob o argumento de que a Lei Estadual n. 12.684/2007 (que proíbe o uso, no Estado de São Paulo, de produtos, materiais ou artefatos que contenham quaisquer tipos de amianto ou outros minerais que, acidentalmente, tenham fibras de amianto na sua composição) seria inconstitucional.

O Tribunal julgou improcedente a ação direta, com a declaração incidental de inconstitucionalidade do art. $2^{\circ} \mathrm{da}$ Lei n. 9.055/1995, vencidos os Ministros Marco Aurélio (Relator) e Luiz Fux, que julgavam procedente a ação, e vencido parcialmente o Ministro Alexandre de Moraes, que julgava improcedente a ação, sem declaração incidental de inconstitucionalidade do art. $2^{\circ}$ da Lei n. 9.055/95. Ausente, justificadamente, o Ministro Gilmar Mendes. Não votou o Ministro Roberto Barroso, sucessor do Ministro Ayres Britto. Nesta assentada, o Ministro Edson Fachin reajustou seu voto para acompanhar o voto do Ministro Dias Toffoli. Redator para o acórdão o Ministro Dias Toffoli. Presidiu o julgamento a Ministra Cármen Lúcia. Plenário, 24.8.2017.

Nesse cenário, a lei estadual paulista continua em vigor e o uso do amianto no estado de São Paulo fica banido.

3. (Des)equilíbrio labor-ambiental e responsabilidade civil do empregador

Todo aquele que provoca dano a outrem, fica obrigado a repará-lo. Além de ser uma das noções jurídicas mais elementares, essa é a disposição do art. 927 do Código Civil. Assim também se dá em relação ao meio ambiente, nele incluído o do trabalho. Nessa perspectiva, acolhendo o princípio do poluidor-pagador, todo aquele que degrada e, portanto, desequilibra o meio ambiente do trabalho, deve repará-lo. É o que se depreende do art. 225, $\S 3^{\circ}$ da Constituição Federal, que assim dispõe: "as condutas e atividades consideradas lesivas ao meio ambiente sujeitarão os infratores, pessoas físicas 
ou jurídicas, a sanções penais e administrativas, independentemente da obrigação de reparar os danos causados" (grifo nosso).

Também nesse sentido segue a legislação infraconstitucional no tocante ao meio ambiente, com destaque para a Lei n. 6.938/1991, que instituiu a Política Nacional do Meio Ambiente, segundo a qual, em seu art. 14, § $1^{\circ}$,

sem obstar a aplicação das penalidades previstas neste artigo, é o poluidor obrigado, independentemente da existência de culpa, a indenizar ou reparar os danos causados ao meio ambiente e a terceiros, afetados por sua atividade. (grifo nosso).

Nessa mesma lógica,

\begin{abstract}
quando o "habitat laboral" se revela inidôneo a assegurar condições mínimas para uma razoável qualidade de vida do trabalhador, teremos aí uma lesão ao meio ambiente do trabalho, e esse complexo de bens materiais e imateriais pode ser agredido e lesado tanto por fontes poluidoras externas como internas, provenientes de outros empreendimentos, trazendo à tona, inclusive, a questão da responsabilização pelos danos, uma vez que os danos ao meio ambiente do trabalho não ficam restritos ao ambiente em que o trabalhador exerce seu labuto, mas o acompanham após o fim do expediente (PADILHA, 2013, p. 181).
\end{abstract}

Observe-se que, em matéria ambiental, aquele que polui o meio ambiente fica obrigado a repará-lo independentemente da existência de culpa, ensejando, assim, a responsabilidade civil objetiva do poluidor ambiental (grifo anterior). Neste tocante, considerando ser o meio ambiente do trabalho parte integrante do meio ambiente geral, é possível estender tal responsabilidade objetiva para aquele (empregador) que provoque desequilíbrios labor-ambientais (?).

Contudo, se em matéria ambiental a lei indicou a responsabilidade objetiva do poluidor; em matéria laboral, há disposição expressa na Constituição Federal, consubstanciada sem seu art. $7^{\circ}$, inciso XXVIII, sobre o direito de todo trabalhador a receber "seguro contra acidentes de trabalho, a cargo do empregador, sem excluir a indenização a que este está obrigado, quando incorrer em dolo ou culpa" (grifo nosso), adotando, portanto, a responsabilidade subjetiva do empregador em caso de acidentes do trabalho.

Tal circunstância traz o questionamento acerca de (aparente) antinomia jurídica no tocante ao tema, contrapondo-se as possibilidades de responsabilidade civil subjetiva do empregador e a responsabilidade objetiva do poluidor. Neste item, serão estudados esses dois modelos de responsabilidade, evidenciando que não se trata de 
antinomia jurídica, mas de disciplinas jurídicas diferentes para situações fáticas igualmente diferentes.

A responsabilidade civil subjetiva do empregador, isto é, aquela informada pela existência de dolo ou culpa, está prevista constitucionalmente no art. $7^{\circ}, \mathrm{XXVIII}$, que dispõe sobre o direito dos trabalhadores perceberem "seguro contra acidentes de trabalho, a cargo do empregador, sem excluir a indenização a que este está obrigado, quando incorrer em dolo ou culpa".

Ao envolver tais elementos subjetivos - dolo e culpa -, a Constituição Federal consagra a responsabilidade civil subjetiva do empregador nos casos de acidente do trabalho (a ele equiparadas as doenças profissionais e do trabalho, conforme previsão do art. 20 da Lei n. 8.213/1991), disciplinada pelos arts. 186 e 927, caput, do Código Civil (culpa aquiliana em sentido lato).

Contudo, ao dispor sobre a responsabilidade daquele que lesa o meio ambiente, a Constituição Federal nada dispôs sobre a necessidade de constatação de dolo ou culpa para respectiva responsabilização, conforme art. $225, \S 3^{\circ}$ (supra). Interpretando sistematicamente o diploma constitucional e considerando seu art. 200, VIII, que deixa claro ser o meio ambiente do trabalho parte do meio ambiente geral, a responsabilização daquele que provoca danos ao meio ambiente do trabalho também não depende de demonstração de culpa ou dolo do agente.

Nessa perspectiva, entende-se que a disposição do art. $7^{\circ}$, XXVIII da Constituição Federal dirige-se àqueles casos em que os danos são oriundos de causalidades tópicas, isto é, problemas e situações pontuais, os quais não têm a magnitude de desequilibrar todo ou parte do meio ambiente laboral. Assim, em resumo, a responsabilidade civil subjetiva do empregador tem lugar quando o dano causado ao meio ambiente do trabalho foi tópico.

Nos casos de danosidade tópica, excepcionando a previsão do art. $7^{\circ}$, XXVIII da Constituição Federal, também é possível haver responsabilidade civil objetiva do empregador nos casos em que a atividade econômica por ele desenvolvida, em função de suas peculiaridades, oferecer riscos especialmente elevados aos trabalhadores, isto é, riscos superiores àqueles inerentes a quaisquer atividades econômicas. É o que dispõe o parágrafo único do art. 927 do Código Civil, segundo o qual "haverá obrigação de reparar o dano, independentemente de culpa, nos casos especificados em lei, ou quando a atividade normalmente desenvolvida pelo autor do dano implicar, por sua natureza, risco para os direitos de outrem" (grifo nosso). Sobre tais riscos inerentes superlativos, esta é a interpretação dada também pelo Centro de Estudos Judiciários do Conselho da Justiça Federal, expressa em seu Enunciado n. 38, indicando que “a responsabilidade fundada no risco da atividade, como prevista na segunda parte do parágrafo único do art. 927 do novo Código Civil, configura-se quando a atividade normalmente desenvolvida 
pelo autor do dano causar a pessoa determinada um ônus maior do que aos demais membros da coletividade".

Para além da danosidade tópica, há danos sistêmicos provocados ao meio ambiente do trabalho, desequilibrando-o no todo ou em parte. Para estes casos, em que se observa um desequilíbrio caracterizador de poluição labor-ambiental, dirige-se o art. 14, $\S 1^{\text {o }}$, da Lei n. 6.938/1991, segundo o qual "sem obstar a aplicação das penalidades previstas neste artigo, é o poluidor obrigado, independentemente da existência de culpa, a indenizar ou reparar os danos causados ao meio ambiente e a terceiros, afetados por sua atividade. [...]". Portanto, o empregador poluidor - isto é, "a pessoa física ou jurídica, de direito público ou privado, responsável, direta ou indiretamente, por atividade causadora de degradação ambiental" (art. 3', inciso IV, da Lei n. 6.938/1991) - fica obrigado a reparar os danos causados ao meio ambiente do trabalho e aos trabalhadores, independentemente de culpa ou dolo.

A fim de identificar um meio ambiente laboral poluído, Feliciano (2013, p. 23) sugere um rol de indícios caracterizadores de um desequilíbrio sistêmico: (a) a afetação multitudinária dos trabalhadores, que são sujeitos às mesmas condições agressivas (e.g. insalubridade, periculosidade, penosidade, etc.) e, por isso, tendem a sofrer lesões semelhantes (PADILHA, 2002); (b) a reincidência, demonstrada por autuações administrativas anteriores com objeto igual ou similar àquele discutido nos autos; $(c)$ a imperícia organizacional, comumente verificável em casos de mudança recente do objeto social da empresa; (d) a constatação pericial de riscos agravados ou proibidos naquele meio ambiente do trabalho. Para ilustrar a danosidade sistêmica e contrapô-la à tópica, o autor relata duas situações:

Imagine-se, e. g., a hipótese de um trabalhador sequelado por choque elétrico porque o seu encarregado esqueceu-se de colocar, na chave geral, o cadeado de segurança, vindo um terceiro a energizar acidentalmente o equipamento em conserto. Todos os procedimentos de segurança são, em geral, observados, ocupando-se a empresa de distribuir EPI bastantes, além de orientar e fiscalizar o uso (Súmula n. 289 do C. TST). O acidente deveu-se, claramente a uma falha humana, não a um quadro de desequilíbrio organizacional ou ambiental. Logo, terá havido causalidade tópica, a atrair a norma do art. $7^{\circ}$, XVIII, da CRFB (...). De outra parte, imagine-se que auditores fiscais do trabalho (MTE) identifiquem cerca de duas dezenas de trabalhadores portadores de disacusia neurossensorial bilateral, todos lotados na mesma seção de certa indústria metalúrgica. Perícias ambientais detectaram níveis locais de ruído variáveis entre 86,6 e 88,0 decibéis, enquanto perícias médicas revelaram que as perdas bilaterais dos empregados oscilam entre $13,52 \%$ e $16,21 \%$. No processo judicial em 


\begin{abstract}
que se reclamam indenizações individuais, as testemunhas ouvidas revelam o fornecimento insuficiente de protetores auriculares, aliado à inocorrência de orientação ou de efetiva fiscalização de uso. Aí estão suficientemente descritos elementos indicativos da causalidade sistêmica dos danos, a atrair a norma do art. $14, \S 1^{\circ}$, da Lei n. 6.938/81. (FELICIANO, 2013, p. 22-23).
\end{abstract}

Nota-se, a partir dos exemplos traçados acima, que, em contraposição à causalidade tópica, a causalidade sistêmica ensejadora de poluição labor-ambiental tem relação direta com a própria organização do meio labor-ambiental, com os métodos de produção, com o desrespeito reiterado de obrigações legais, tratando-se de um desequilíbrio gestáltico.

Assim, conforme exposto é possível identificar três regramentos jurídicos (coerentes entre si) a respeito da responsabilização civil do empregador: $(i)$ responsabilidade civil subjetiva do empregador em função de danos tópicos, fundada em dolo ou culpa (prevista no art. $7^{\circ}$, XXVIII, da Constituição Federal e regulada pelos arts. 186 e 927 , caput, do Código Civil); (ii) responsabilidade civil objetiva do empregador decorrente de um risco especialmente elevado (risco inerente superlativo) gerado por sua atividade econômica (prevista no art. 927, parágrafo único, do Código Civil); (iii) responsabilidade civil objetiva do empregador decorrente do desequilíbrio do meio ambiente (poluição labor-ambiental), fundada no art. 14, $\S 1^{\circ}$, da Lei n. 6.938/1981, aplicável nos casos de danosidade sistêmica.

\title{
Conclusão
}

Considerando a disposição constitucional expressa sobre a configuração do meio ambiente do trabalho como parte integrante do meio ambiente humano (art. 200, inciso VIII da Constituição Federal), aplicam-se às questões de saúde e segurança do trabalho - e, de modo mais abrangente, a todo o Direito Ambiental do Trabalho - os princípios protetores do Direito Ambiental; e, notadamente, o princípio da prevenção, o princípio da precaução, o princípio da melhoria contínua, o princípio da informação, o princípio da participação e o princípio do poluidor-pagador. Aplicam-se, mais, naquilo que for compatível, as leis que regem a proteção do meio ambiente, e, em especial, a Lei n. $6.938 / 1981$.

Nessa perspectiva, os riscos inerentes à presença do amianto no meio ambiente do trabalho, não podem ser corretamente avaliados, se não à luz dos princípios jurídicos acima relacionados. Sob o pálio da prevenção/precaução, resulta certo que a exposição de trabalhadores às diversas modalidades de amianto - inclusive o crisotila deve ser prioritariamente eliminada e evitada; e assim haveria de ser, mesmo se houvesse 
incerteza científica a respeito de seu potencial cancerígeno (o que, a rigor, já não há, mercê dos próprios comunicados da Organização Mundial da Saúde).

Onde a eliminação não ocorra prontamente, ademais, à vista do modelo federativo brasileiro e das recentes decisões do STF, deverão ter curso todas as medidas adequadas para que os riscos sejam progressivamente diminuídos (princípio da melhoria contínua) e plenamente informados aos trabalhadores (princípio da informação), que, por sua vez, devem ser chamados a dialogar sobre as melhores estratégias de segurança laboral (princípio da participação) até o banimento final.

De resto, em relação aos danos laborais derivados do amianto já utilizado pela indústria nacional, está o empregador obrigado a reparar os danos que sua atividade causou (princípio do poluidor-pagador), independentemente de culpa ou dolo. Em outras palavras, o empregador-poluidor que manteve seus trabalhadores expostos ao amianto deverá ser responsabilizado objetivamente, seja porque sua atividade é superlativamente mais lesiva aos trabalhadores (art. 927, parágrafo único, do Código Civil), seja ainda se assim não se entender - porque ambientes laborais expostos ao amianto ou por ele contaminados estão indelevelmente desequilibrados.

Como há um século e meio ponderou Abraham Lincoln, "[y]ou cannot escape the responsibility of tomorrow by evading it today". Que assim seja, agora e doravante, para todas as chagas que a crisotila nos legou, e à posteridade.

São Paulo, agosto de 2017.

\section{Referências}

BRASIL. Ministério da Saúde. Instituto Nacional de Câncer José de Alencar Gomes da Silva. Amianto: prevenção e fatores de risco. Disponível em: <http:/www2.inca.gov.br/wps/wcm/ connect/cancer/site/prevencao-fatores-de-risco/amianto>. Acesso em: 13 set. 2017.

BRASIL. Ministério da Saúde. Instituto Nacional de Câncer José de Alencar Gomes da Silva. Coordenação Geral de Ações Estratégicas, Coordenação de Prevenção e Vigilância, Área de Vigilância do Câncer relacionado ao Trabalho e ao Ambiente. Fátima Sueli Neto Ribeiro (Org.). Diretrizes para a vigilância do câncer relacionado ao trabalho. Rio de Janeiro: Inca, 2012b. Disponível em: <http://www1.inca.gov.br/inca/Arquivos/comunicacao/diretrizes_cancer_trabalho. pdf $>$.

BRASIL. Pelo menos 19 tipos de câncer podem estar relacionados ao trabalho. Rio de Janeiro: [s.n.], 2012a. Disponível em: <http:/www2.inca.gov.br/wps/wcm/connect/comunicacaoinformacao/site/ home/sala_imprensa/releases/2012/pelo_menos_19_tipos_cancer_podem_estar_relacionados_ trabalho>. Acesso em: 11 set. 2017. 
CLERC, J. M. Training as an instrument of a strategy for the improvement of working conditions and environment. International Labour Review, v. 121, 1982, p. 565.

DERANI, Cristiane. Direito ambiental econômico. 3. ed. São Paulo: Saraiva, 2008.

FELICIANO, Guilherme Guimarães. Meio ambiente do trabalho: aspectos gerais e propedêuticos. Revista do Tribunal Regional do Trabalho da $15^{a}$ Região, Campinas, n. 20, 2002.

FELICIANO, Guilherme Guimarães. O meio ambiente do trabalho e a responsabilidade civil patronal: reconhecendo a danosidade sistêmica. In: FELICIANO, Guilherme Guimarães; URIAS, João (Coord.). Direito ambiental do trabalho. Apontamentos para uma teoria geral: saúde, ambiente e trabalho: novos rumos da regulamentação jurídica do trabalho. São Paulo: LTr, 2013. v. 1. p. 1125.

MACHADO, Paulo Affonso Leme. Direito ambiental brasileiro. 18 ed. rev., atual. e ampl. São Paulo: Malheiros, 2010.

MARANHÃO, Ney Stany Morais. Meio ambiente do trabalho: descrição jurídico-conceitual. In: FELICIANO, Guilherme Guimarães (Coord.) et al. Direito ambiental do trabalho: apontamentos para uma teoria geral. São Paulo: LTr, 2017. v. 3.

MELO, Raimundo Simão de. Direito ambiental do trabalho e a saúde do trabalhador. 5 ed. São Paulo: LTr, 2013.

OCCUPATIONAL SAFETY AND HEALTH ADMINISTRATION. Asbestos. OSHAFactSheet, 2014. Disponível em: <https://www.osha.gov/Publications/OSHA3507.pdf>.

OLIVEIRA, Sebastião Geraldo de. Proteção jurídica à saúde do trabalhador. 2 ed. rev., ampl. e atual. São Paulo: LTr, 1998.

ORGANIZAÇÃO DAS NAÇÕES UNIDAS. Declaração de Estocolmo sobre o ambiente humano - 1972. 1972. Disponível em: <http://www.direitoshumanos.usp.br/index.php/Meio-Ambiente/ declaracao-de-estocolmo-sobre-o-ambiente-humano.html>. Acesso em: 10 set. 2017.

ORGANIZAÇÃO DAS NAÇÕES UNIDAS. Declaração do Rio sobre meio ambiente e desenvolvimento. 1992. Disponível em: <http://www.onu.org.br/rio20/img/2012/01/rio92.pdf>. Acesso em: 10 set. 2017.

ORGANIZACIÓN MUNDIAL DE LA SALUD. Asbesto crisotilo. 2015. Disponível em: <http:// apps.who.int/iris/bitstream/10665/178803/1/9789243564814_spa.pdf?ua=1\&ua=1>. Acesso em: 11 set. 2017.

ORGANIZACIÓN MUNDIAL DE LA SALUD. Eliminación de las enfermedades relacionadas con el asbesto. 2016. Disponível em: <http://www.who.int/mediacentre/factsheets/fs343/es/>. Acesso em: 12 set. 2017.

PADILHA, Norma Sueli. Do meio ambiente do trabalho equilibrado. São Paulo: LTr, 2002. 
PADILHA, Norma Sueli. Meio ambiente do trabalho: um direito fundamental do trabalhador e a superação da monetização do risco. Revista do Tribunal Superior do Trabalho, v. 79, n. 4, p. 173182, out./dez. 2013.

PRIEUR, Michel. Droit de l'environnement. 4. ed. Paris: Dalloz, 2001. 